\title{
O MERCOSUL E A SEGURANÇA REGIONAL uma agenda comum?
}

Shiguenoli Miyamoto

Resumo: Desde o início do processo de integração regional, têm falado mais alto os interesses particulares dos Estados, cada um procurando resolver seus próprios problemas domésticos. Nesse contexto, a indefinição de uma agenda mais consistente dificulta a integração regional em todos os planos, sobretudo, em áreas sensíveis como as de políticas externa e de defesa, muito complexas para serem elaboradas em conjunto.

Palavras-chave: Mercosul; integração regional; segurança regional.

Abstract: Despite movement towards regional integration, countries continue to place priority on their national interests, seeking first and foremost to address their particular domestic issues. The resulting lack of a cohesive agenda hinders regional integration, particularly in the areas of foreign policy and defense - issues that, by reason of their complexity, defy group consensus.

Key words: Mercosul; regional integration; regional security.

$\mathrm{D}$ e maneira simplificada, pode-se dizer que há duas grandes vertentes para analisar as relações internacionais: a óptica conflitiva e a que privilegia a integração, ou, dito de outra forma, abordagens que defendem a paz e a guerra.

Provavelmente, em nenhum momento da História, mesmo em tempos mais remotos, encontrou-se elementos suficientes para afirmar que dois ou mais atores tenham-se relacionado entre si apenas de maneira amistosa. Ou que se tenha verificado a existência de um quadro no qual a guerra tivesse sido permanente, uma luta de todos contra todos.

Na realidade, essas duas visões sempre caminharam pari passu ao desenrolar da história da Humanidade. E permearam o relacionamento entre os diversos Estados, ou grupos, quando aqueles não haviam-se constituído formalmente, a partir de 1648, com o Tratado de Vestfalia, de acordo com as interpretações correntes.

A idéia hobbesiana de "estado da natureza" nada mais é do que um modelo típico ideal, segundo os moldes weberianos, e nunca comprovado empiricamente (Forsyth, 1980). Trata-se de um recurso teórico, para que ele justificasse a criação do Estado, por meio de um pacto entre os diversos agentes, assegurando, a eles, condições mínimas para que sobrevivessem com relativa tranqüilidade, dentro de um mundo com regras preestabelecidas.

As relações entre os diversos Estados dão-se ao mesmo tempo por dois prismas: da cooperação e o do conflito. Quando interesses comuns apresentam-se, a cooperação é o caminho preferido. As divergências, por sua vez, fazem parte das regras do jogo e, no limite, levam a acirramentos, e o resultado final só é conhecido nos campos de batalha. Como lembra Raymond Aron (1962:1030), o "sistema internacional é o conjunto constituído por unidades políticas que mantêm entre si relações regulares e que são suscetíveis de entrar em guerra total".

De resto, as normas e convenções que dão formato ao sistema internacional continuamente se apresentam instáveis, em um contexto em que prevalecem regras imprecisas e cambiantes (Sardenberg, 1982). Isso, é evidente, contribui para que governos e Estados privilegiem seus próprios interesses - cada vez mais fortes -, confiando com reserva nos demais, desde os vizinhos mais próximos, até os mais distantes com os quais mantêm intercâmbio satisfatório.

A cooperação, ao lado da competição e do conflito, sempre existiu, e nunca houve necessidade de grandes 
debates para chegar a essa conclusão. Não é, gratuitamente, que a maior parte da literatura que trata das relações internacionais centre sua atenção em um desses prismas.

A cooperação entre os diversos Estados é uma constante, embora não permanente, ao longo dos séculos. Ao se comportarem dessa forma, os agentes consideram a possibilidade de obter uma série de dividendos, calculando custos e benefícios. Entre estes últimos, a desnecessidade de se preocupar com gestos agressivos ao longo de suas fronteiras, ameaças à sua soberania e a chance de viver, portanto, mais tranqüilos.

Tomadas em conjunto, tais medidas tornaram viável elaborar e executar, com maior regularidade e consistência, as políticas públicas, atendendo aos interesses dos senhores feudais, do Estado e da sociedade.

Essa cooperação implicou no seguimento de algumas regras comuns, amparadas no princípio de que todos sairiam ganhando. Quando os interesses gerais eram superiores, a cooperação foi privilegiada. O contrário deu-se quando os benefícios ficavam aquém do esperado ou desejado. A quebra de acordos enquadra-se na lógica de que eles são bons apenas enquanto todos lucram.

Há entendimento de que a cooperação, por mais bem intencionada que seja, sempre é limitada, restrita a itens específicos de uma pauta de negociações. Assim, a cooperação pode ser feita no âmbito econômico, abarcando um ou outro setor, mas não necessariamente o mesmo se verifica nos planos político ou militar. Isso significa dizer que cada um dos lados mantém pleno domínio sobre suas propriedades, seus domínios, seus territórios, não deixando margens a dúvidas sobre sua soberania, conceito tão caro aos Estados e governantes, ainda que sob a égide da interdependência e da globalização.

Por outro lado, o aprofundamento da cooperação, como nos últimos anos tem-se observado, em busca de uma efetiva integração, rompe com o tradicional conceito de soberania. A integração, entendida como deve ser e tomada às últimas conseqüências, leva à quebra da soberania, constituindo-se instâncias supranacionais, com centros de decisão coletivos e não mais individuais, em que o bem comum é o objetivo primordial a ser alcançado.

Como esclarecem alguns autores, por integração devese entender o "processo pelo qual os atores políticos em vários marcos nacionais diferentes são persuadidos da necessidade de dirigir suas finalidades, expectativas e atividades políticas para um centro novo e maior, cujas instituições possuam ou exijam jurisdição sobre os Estados nacionais já existentes”. (Haas, 1964:28).
$\mathrm{O}$ aprofundamento das relações bilaterais ou multilaterais, rumo à integração, entre dois ou mais países, e construindo blocos, consiste na definição de uma agenda única para esses Estados, abrangendo aspectos políticos, econômicos, militares, culturais, etc. As políticas não seriam objeto de apenas uma ou de outra unidade, mas de responsabilidade de todos que firmariam tal pacto, constituindo instâncias maiores.

A adoção desse tipo de comportamento levaria a atingir o que há, pelo menos, oitocentos anos a literatura internacional aborda, ou seja, a criação de um governo mundial, no qual o conflito cede lugar à paz, e ela impulsionando o relacionamento entre todos, independentemente de suas diferenças políticas, culturais, religiosas, etc.

$\mathrm{O}$ que se verifica, sobretudo, nos anos mais recentes, em diversas ocasiões, tanto na Europa, na América do Norte, quanto na América Latina, é que as propostas de integração têm caminhado mais devagar do que seria possível ou desejável. Obstáculos quase insuperáveis têm surgido em todos os instantes, com resistências de um ou outro parceiro, procurando cada um gerenciar, sempre, as políticas regionais em favor de suas vontades particulares.

\section{INTEGRAÇÃO E TEMAS SENSÍVEIS}

Muitos tópicos, por sua delicada natureza, são difíceis de negociar, e apresentam sérios percalços para chegar a um denominador comum. Entre esses, os que dizem respeito à segurança do Estado e a atuação do país no cenário mundial apresentam-se como os mais importantes e complicados, para a definição de políticas convergentes.

Há motivos plausíveis que justificam as reticências dos governantes sobre esses assuntos. Sentar à mesa de negociações, discutir, barganhar, ceder e tomar decisões conjuntas, significa abrir mão da feitura de políticas atendendo tão-somente aos seus anseios, como até então estavam acostumados. Para os decision-makers, essa nova situação os obrigaria a ver, por outro prisma, seus Estados como o elemento mais importante do sistema internacional. Aparentemente verificam-se, portanto, irreconciliáveis contradições, com as falas pregando a colaboração e a prática indicando o contrário.

Contradizendo os discursos, o Estado-Nação continua, nos dias atuais, mais sólido do que nunca. Os acontecimentos da última década, com as posturas assumidas pelas grandes potências para salvaguardar seus interesses e ampliar suas influências, são incisivos ao comprovar que a globalização, tal como é propalada, está longe de elimi- 
nar categorias como fronteira, soberania, nacionalismo, etc. Como foi possível constatar, em nome dos interesses nacionais, países como Estados Unidos, França, Canadá, Índia ou China realizaram vigorosas políticas.

Os Estados Unidos em nenhum momento abdicaram de seu poder, fosse no plano econômico, fosse no militar. Lançando mão de duras medidas, a Casa Branca ameaçou um sem número de vezes retaliar outros países, acionando a Super Cláusula 301, da Lei de Comércio Americana. Tal atitude foi tomada inclusive contra o Canadá, seu parceiro maior no Nafta, com quem mantém relações especiais desde os anos 50. O mesmo acontece quando se confrontam e seus interesses chocam-se com os de seus principais competidores, europeus, ou japoneses, ainda que todos ocupem o topo da pirâmide (Sardenberg, 1989:255-72; Thurow, 1993).

Além dos protecionismos econômicos, o bloqueio de movimentos migratórios para seus territórios e os xenofobismos converteram-se em moeda corrente utilizada no cotidiano das grandes nações industrializadas, contra os parceiros menores do mundo em desenvolvimento.

No plano militar, os Estados Unidos não se esqueceram do direito de ditar pela força, o que consideram correto, de acordo com seus pontos de vista, ao interferir em todos os quadrantes, onde seus interesses, ou suas empresas, pudessem sofrer quaisquer tipos de danos. Intervenções como as ocorridas no Iraque em 1991, e no Kosovo pouco depois, independentemente de autorização da Organização das Nações Unidas, enquadram-se nesse raciocínio (Vicentini, 1998).

Como diria Bill Clinton "precisamos compreender o que temos em jogo nos Balcãs e em Kosovo (...) esta é uma crise humanitária, porém, é muito mais do que isso: é um conflito sem fronteiras naturais, que ameaça nossos interesses nacionais". 1

A França e a China adotaram comportamentos parecidos, pouco se importando com as críticas, quando resolveram reforçar seus arsenais militares. Primeiro detonaram, cada uma delas, meia dúzia de bombas nucleares, antes de assinar o Tratado de Rarotonga desnuclearizando o Pacífico Sul em 1996. Em julho de 2001, os Estados Unidos continuaram com seus testes, desta vez com o escudo antimíssil. Outros países como a Índia e o Paquistão também exercitaram políticas de poder, realizando seus experimentos nucleares, não obstante as ameaças das grandes potências, pautando-se pelo raciocínio de que "se os outros fazem, o que nos impede"?

O aumento das capacidades econômicas e militares das grandes potências, reafirmando seu papel de guardiãs do mundo, foi a tônica do período pós-guerra fria. Essa tendência contrariou, assim, os mais otimistas que esperavam o surgimento, no limiar do terceiro milênio, de um cenário inteiramente distinto, isento de ameaças e de guerras.

Os conflitos que explodiram com violência avassaladora, justamente em função do término das divergências LesteOeste, serviram para corroborar, uma vez mais, que os Estados Nacionais continuam tão ou mais importantes do que antes. Verificou-se, em pouquíssimo tempo, a fragmentação de impérios, como a União Soviética, e de países como a Iugoslávia e a Checoslováquia, dando surgimento a várias unidades menores, independentes, soberanas. Em todo o mundo uma infinidade de reivindicações, até então camufladas, emergiu com vigor, objetivando criar novos países, desde o sul do Brasil ao Nepal, passando pelo Texas, pelo Quebec, pela Itália com a República da Padânia, pelos curdos, pelo Timor Leste, pelos palestinos, pelo Tibete e pelos ianomâmis, sem esquecer os bascos que continuaram sua antiga luta.

A derrocada do império soviético e o esvaziamento do Pacto de Varsóvia (extinto oficialmente em 1991) não foram motivos suficientes para o arrefecimento das políticas de poder, não havendo contrapartida ocidental. Em 1991, a Organização do Tratado do Atlântico Norte (Otan) deixou de ser exclusivamente defensiva, e mudou seu papel. Ao adotar novo conceito estratégico, ampliou seu raio de ação, o que lhe permitiu operar em qualquer lugar, se e quando a segurança européia estiver em risco (Otan, 1991). Não é fortuitamente que textos como os de Samuel Huntington (1994) tiveram considerável impacto nos mesmos anos, com a eleição de novos inimigos do mundo ocidental (Huntington, 1994).

Contudo, estes são comportamentos habituais das grandes potências, que produzem e executam políticas, para atender às suas necessidades, e de acordo com as capacidades acumuladas ao longo do tempo. Nada diferente, portanto, da realpolitik, que serve de fio condutor para os "donos do mundo", que nunca pedem licença a ninguém, além de surdos e insensíveis a apelos e protestos de quaisquer natureza.

Afinal de contas, dita a política de poder, quem garante que o fim de um conflito significa o início de um estágio, em que todos elegem como prioridade os interesses coletivos, substituindo os tradicionais egoísmos individuais?

Os últimos dois mil anos orientam os que decidem os rumos de seus países. Esses levam na devida conta, não o advento de um período de paz duradouro, mas vêem o atual 
estágio apenas como um breve interregno entre outros conflitos que, é claro, virão.

As atitudes que modelam as relações internacionais estão longe de obedecer às concepções idealistas, guiandose por posturas realistas, em que os interesses ecoam com intensidade cada vez maior. As boas intenções, muitas delas assinadas, são negociadas com base em posições de força e de poder. Os resultados obtidos nas negociações demonstram claramente as capacidades utilizadas em todos os sentidos, particularmente no militar, que dá credibilidade a todos as demais, quando se coloca a necessidade de intervir, pressionar e impor boicotes a outros países.

A literatura clássica utilizada para explicar as relações internacionais, parcialmente rejeitada em nome das novas teorias, não teve o seu fim decretado, como se divulga em muitas oportunidades. Sua utilização apenas não é mais feita com a mesma intensidade, como ocorria em dias passados, em todas as ocasiões, dividindo agora o cenário com outras variáveis, como a econômica, a cultural, etc. Entretanto, isso deve ser interpretado como algo que não foge à normalidade, visto que as relações internacionais caracterizam-se por ser essencialmente dinâmicas, nunca havendo dois momentos iguais quando se deseja. Os atores, os lugares, as circunstâncias e as motivações foram e são diferentes no transcorrer da História.

Por esse prisma, determinadas políticas - externa, de defesa e de segurança - encontram dificuldades para ser compartilhadas, já que colocariam em risco a própria sobrevivência dos Estados e, por extensão, de suas sociedades. Essa interpretação pode ser considerada verdadeira, pelo menos enquanto perdurarem desconfianças mútuas, como até agora tem prevalecido.

Não custa relembrar quais os objetivos de uma política externa, ainda que recorrendo a antigas obras como as de Karl Deutsch (1970). Segundo ele, "a política exterior de cada país se refere, em primeiro lugar, à preservação de sua independência e segurança, e, em segundo lugar, à perseguição e proteção de seus interesses econômicos".

Se isso é observável no cotidiano das grandes nações, que disputam espaços, poderes e influências, estruturando o sistema internacional e estabelecendo padrões e ordens mundiais, segundo suas conveniências, nada mais natural que os demais países adotem idêntico padrão de comportamento. Por que agir de outra forma, se os grandes países utilizam o expediente das políticas de poder para resolver quaisquer problemas que lhes digam respeito?

Há abismos enormes entre os discursos de boas intenções, de união, de cooperação e de integração, e aquilo que na prática é implementado de maneira comedida. Isso se dá tanto na questão ambiental, no comércio internacional, nos direitos humanos, como nas áreas de defesa e segurança.

Quando é conveniente, as grandes potências esquecemse até mesmo dos argumentos em defesa da preservação do meio ambiente e dos direitos humanos, quando emergem outros interesses, como fazem os Estados Unidos. As críticas intensas ao governo chinês, por desrespeitar esses dois itens, motivos alegados para impedi-lo de ingressar na Organização Mundial do Comércio (OMC), esfumaçaram-se, quando se chegou à conclusão de que é melhor ter a China dentro do que fora da OMC.

Ou então, como fez o presidente atual, George W. Bush, ao rejeitar o Protocolo de Kyoto sobre a emissão de poluentes, sequer lembrando-se da Conferência Mundial das Nações Unidas sobre Meio Ambiente e Desenvolvimento, a ECO 92, realizada no Rio de Janeiro, quando as ricas nações industrializadas comprometeram-se a ceder $0,7 \%$ de seus PIB, em tecnologias e recursos aos países em desenvolvimento.

Obviamente, essa percepção das relações internacionais cria dificuldades crescentes, impedindo colaboração mais estreita, mesmo em regiões mais afastadas dos grandes centros de decisão, como os países do Mercosul, objeto de análise a seguir.

\section{EXPERIÊNCIA LATINO-AMERICANA}

$\mathrm{Na}$ segunda metade do século passado, o continente latino-americano passou por várias experiências de cooperação e de integração, que nunca conseguiram alcançar os objetivos inicialmente traçados. Os países da região enfrentaram várias dificuldades, por conta não só do quadro doméstico, mas também por causa das conjunturas regionais e internacionais. Conte-se, ainda, o próprio otimismo exagerado quando da confecção dos acordos. Esses problemas, no todo ou em parte, contribuíram para minar as tentativas integracionistas.

A Associação Latino-Americana de Livre Comércio (Alalc), criada em 1960 com o Tratado de Montevidéu, é um exemplo que reforça essa interpretação. A tentativa que nasceu calcada na boa vontade dos países de todo o continente, logo começaria a ver solapada na pretensão de solucionar os problemas locais.

As mudanças de regime verificadas logo depois, com a implantação de governos ditatoriais, que competiam entre si por influências na América Latina, embora fos- 
sem todos anticomunistas, com a bênção e a ajuda do grande irmão do Norte, e as interpretações distintas sobre a essência do acordo, pesaram de modo decisivo para $o$ fracasso da entidade.

De um lado, brasileiros e argentinos tinham projetos diferenciados de inserção regional e internacional, acirrando as disputas que tradicionalmente movimentaram a história da Bacia do Prata. As políticas públicas brasileiras concernentes à ocupação das fronteiras, corredores de exportação e abastecimento, populacional e energética, eram alvo freqüente de intensas críticas, por serem consideradas parte de um projeto geopolítico expansionista. Com esse clima, é claro que qualquer projeto de colaboração mais próximo tinha poucas chances de ser coroado de êxito.

Por outro lado, enquanto os países menores desejavam que o processo desse prioridade ao desenvolvimento de todos - em que eles, em particular, seriam ajudados -, os maiores não compartilhavam de igual ponto de vista (Barbosa, 1991).

Para as grandes nações, a Alalc era mais um pretexto, por assim dizer, uma instituição que facilitaria a entrada de seus produtos em outros mercados, por menores que eles fossem. Tratava-se de uma visão estritamente comercial, e não desenvolvimentista. Com essa dicotomia, o regionalismo não poderia caminhar a contento.

O prazo fixado, de maneira otimista, para que o projeto se concretizasse, foi várias vezes alterado. As intempéries que os países enfrentaram, ao mesmo tempo, diante da turbulência internacional - como as crises do petróleo - e a impossibilidade de honrar seus compromissos - como o pagamento da dívida externa - ajudaram a sepultar o sonho inicial. Tanto é assim que, em 1980, a Alalc foi substituída por outra organização - cujo foro também se localizava em Montevidéu -, a Associação Latino-Americana de Integração (Aladi). O nome ambicioso propunha, não apenas a emergência de uma zona de livre-comércio, mas algo maior, integrar o continente.

Nesse meio tempo outras propostas, com escopo mais reduzido, foram igualmente encaminhadas. Em 1969, pelo Tratado de Cartagena, criou-se o Pacto Andino. Pelo Tratado de Cooperação Amazônica (TCA) - firmado pelo Brasil com mais sete países da região em julho de 1978 - pensou-se na possibilidade de integrar a região norte do continente, e defendê-la contra interesses externos que se mostravam cada vez mais presentes (Ministério das Relações Exteriores, 1978). Todavia, o TCA passou por incontáveis dificuldades, desde o início, como a falta de recursos financeiros, não conseguindo levar avante suas tarefas.

As denúncias sobre a depredação do meio ambiente, os maus cuidados com as populações florestais, e o uso dos recursos minerais pelas empresas estrangeiras que aqui se estabeleciam, precisavam ser respondidas. Impunha-se, pois, uma postura mais agressiva por parte do governo brasileiro, que tomou algumas iniciativas para proteger a floresta tropical, primeiro com o Projeto Calha Norte e, em seguida, com o Sivam/Sipam - Sistema de Vigilância da Amazônia/Sistema de Proteção da Amazônia (Conselho de Segurança Nacional, 1985; Câmara dos Deputados, 1996).

Tendo surgido em conjuntura desfavorável, já que os anos 80 constituíram-se em período difícil para o continente, a Aladi pouco realizou. Com a mudança do panorama político, ou seja, a redemocratização dos países castrenses latino-americanos, as alterações na conjuntura internacional, os Estados Unidos contrários à forma como as instâncias multilaterais estavam atuando e a Rodada GATT do Uruguai, a criação de blocos regionais adquiriu força, e tornou-se não apenas conveniente, mas imperiosa para enfrentar em melhores condições a voracidade competitiva que seria marca dos anos 90 .

A subida de civis aos governos argentino e brasileiro já fora um bom sinal para o continente. Enterrando, pelo menos a princípio, as velhas discórdias regionais, Buenos Aires e Brasília assinaram em 1985 os protocolos de integração regional, absorvendo depois o Uruguai e o Paraguai, constituindo o Mercado Comum do Cone Sul (MERCOSUL). Logo, o Mercosul passou a alimentar a esperança de crescer, ingressando no continente.

A década de 90 serviu para mostrar ao Mercosul que apenas as intenções não seriam suficientes para que empreendimento de tal magnitude tivesse sucesso assegurado, ainda mais em período tão curto, esquecendo-se que o continente europeu tenta, há muito tempo, a mesma coisa, caminhando devagar em busca desse destino.

As polêmicas diárias em praticamente todos os setores dá o tom que caracterizou o relacionamento sob a rubrica do Mercosul. Com críticas, ora sobre a inoperância dos acordos, ora sobre quem ganha e quem perde, ou sobre as diferenças de concepção do que seja o processo regional, ameaçando por fim a tal iniciativa, o Mercosul marchou, até o momento, apoiado em frágeis muletas. A situação delicada que a Argentina enfrentou em meados de julho, é outro indicador de como é difícil negociar quando tantos e tão diferentes interesses estão em jogo. 


\section{POLÍTICA EXTERNA E DE DEFESA: CONVERGÊNCIA DE INTERESSES?}

Durante décadas, os dois maiores países da América do Sul competiram de forma extraordinária. Em várias ocasiões, como no contencioso de Itaipu/Corpus, a situação chegou a momentos delicados (Caubet, 1989).

Os argentinos criticavam o uso do Rio Paraná pelo governo brasileiro, acusando-o de colocar avante um projeto geopolítico de hegemonia regional. Não era, porém, só contra Brasília que Buenos Aires brandia sua cólera. O Chile também tinha um impasse com o governo portenho, pelo controle do Canal de Beagle. Nos anos 80 , os generais argentinos que controlavam o poder, ousaram entrar em guerra contra o reino de sua majestade britânica pelas ilhas Malvinas.

Brasília, além do confronto com Buenos Aires, tinha pouco com que se preocupar. Em 1986, propôs, na ONU, a criação da Zona de Paz e de Cooperação no Atlântico Sul (Zopacs) (MRE, 1986). O país também não quis apoiar, na década de 70 , a constituição de um tratado que envolvia os países da região em uma congênere como a do Atlântico Norte, com o nome de Pacto do Atlântico Sul, ou Organização do Tratado do Atlântico Sul. Por motivos já expostos em outros trabalhos, essas iniciativas não agradavam ao governo brasileiro (Miyamoto, 1985).

Com a redemocratização do continente, o princípio que passou a vigorar é que as disputas deveriam ceder lugar a outros propósitos. Para os argentinos era muito melhor, recuperar os anos perdidos, tanto com a guerra contra os ingleses, quanto com a energia despendida contra brasileiros e chilenos.

O mesmo se sucedia pelo lado brasileiro. Por isso, a Bacia do Prata deixou de ser palco privilegiado de atenção do governo brasileiro, como política de defesa. Além do final do contencioso de Itaipu, a subscrição do tratado da Zopacs dava boa margem de segurança para que assim se pensasse.

Novas preocupações passaram a orientar Brasília, agora dirigidas para a região Norte do País, rumo às densas florestas amazônicas. A ascensão do coronel Desi Bouterse, que se autoproclamava portador de tendências marxistas, ao governo de Paramaribo, além das persistentes críticas contra os desmandos praticados pelos países amazônicos aos seus recursos naturais, fizeram com que aquela parte do continente se convertesse em primazia do governo brasileiro. O surgimento do Projeto Calha Norte, em 1985, e depois do Sivam/Sipam retratam essas preocupações.
No próprio documento intitulado "Política de Defesa Nacional", datado de 1996, e que fixa as diretrizes estratégicas brasileiras, a Amazônia ocupa a parte central. Este texto antecedeu a criação do Ministério da Defesa em 1999 (Presidência da República, 1996). Na realidade, vários outros documentos já enfatizavam, há muito tempo, a questão amazônica, como tema de importância na estratégia nacional (Cebres, 1991; Escola Superior de Guerra, 1990; Revista Brasileira de Política Internacional, 1968).

Ao elegerem tal região como prioridade, brasileiros, bolivianos, venezuelanos, equatorianos - que guerrearam duas vezes contra os peruanos -, além dos colombianos às voltas com graves problemas, nada mais fizeram do que colocar, em primeiro lugar, a necessidade de proteger seus territórios, suas instituições, portanto, sua soberania. Para isso, mantiveram aparatos bélicos, adquirindo equipamentos sempre que possível, e de acordo com seus exíguos orçamentos. A própria Comissão Econômica para a América Latina (Cepal), em estudo recente, mostra que as preocupações com esta atividade nunca deixaram de existir. (Lahera e Ortuzar, 1998).

Os Estados agem (ou tentam) como unidades independentes, soberanas, fazendo com que a política externa auxilie na manutenção da segurança nacional, tornando-se parte constante do cálculo governamental. Destarte, a despeito do término das discórdias estratégico-militares entre argentinos, brasileiros e chilenos, tal constatação não significa forçosamente a possibilidade de se modelar políticas comuns, revelando seus equipamentos militares (se bem que todos sabem o que cada vizinho possui ou adquire), suas preparações e suas estratégias para enfrentar e superar os diversos antagonismos que possam surgir.

As Forças Armadas brasileiras e argentinas aproximaram-se desde o final dos anos 80 , realizaram exercícios conjuntos, desativaram seus programas nucleares (o Brasil encerrou as atividades da Serra do Cachimbo), e participaram de dois eventos entre os Estados Maiores das Forças Armadas, além dos encontros de Ministros das Defesa das Américas, desde Williamsburg em 1995 à realizada em 2000 em Manaus, mas nem por isso, tomam iniciativas visando produzir políticas uniformes.

Os discursos e o comportamento das autoridades do setor são bem significativos a esse respeito. Deixam aberta a possibilidade de integração, mas ressalvam que ainda é prematuro partir para tais medidas, e que isso, por enquanto, não é prioridade.

Enquanto não enfrentam problemas comuns, cada um realiza suas políticas individualmente como sempre fez. 
A Argentina está mais voltada para a questão do terrorismo contra a comunidade judaica (como ocorreu nos anos 90 ), com o tráfico de drogas e armamentos e com a presença de grupos islâmicos na fronteira tripartite argentino-brasileiro-paraguaia. A preocupação brasileira, por força das circunstâncias, acha-se dirigida para o território amazônico, apesar de não negligenciar o tráfico de drogas como uma de suas prioridades.

Por razões como essas, não sentem necessidade de aprofundar a cooperação - já existente no âmbito da Justiça -, enquanto dão conta, sozinhos, de seus problemas. Na verdade, não se trata apenas disso. Cada um deles raciocina dentro de estreitos parâmetros de defesa dos interesses e de projeção de seus Estados nacionais. Daí, ter-se observado uma prematura disputa por vaga no Conselho de Segurança da Organização das Nações Unidas, no caso de uma possível reestruturação dessa entidade. Situação parecida verificou-se quando a Argentina solicitou o status de aliado preferencial da Organização do Tratado do Atlântico Norte. Ou ainda, assumindo posições isoladas - porém em perfeita sintonia com os Estados Unidos - para atuar em conflitos internacionais, como fez na Guerra do Golfo em 1991, ao enviar duas embarcações para aquela zona de conflito.

Em abril de 1987, quando se realizou, em Buenos Aires, o $1^{\circ}$ Simpósio de Estudos Estratégicos Argentino-Brasileiro, na abertura do encontro o brigadeiro-general Teodoro Guillermo Waldner, chefe do Estado-Maior Conjunto das Forças Armadas Argentinas, chamava a atenção para a importância do evento, já que "em algumas oportunidades, através da história, esgrimimos [argentinos e brasileiros] objetivos antagônicos". A seguir frisava que "juntos, Brasil e Argentina podem chegar a conformar um espaço geopolítico que lhes permitirá alcançar um dimensionamento de nível mundial" (Waldner, 1987: 291-92).

O mesmo discurso otimista foi feito, exatamente um ano depois, por ocasião do $2^{\circ}$ Simpósio, dessa vez em São Paulo, pelo general de divisão Edson Alves Mey, vicechefe do Estado-Maior do Exército brasileiro (Mey, 1988:341-42).

Os anos 90, porém, encarregaram-se de trazer à tona, os óbices - como dizem os militares - para atingir o objetivo, tão apregoado nos discursos oficiais. As iniciativas isoladas de cada parceiro, em quase todas as instâncias, políticas e econômicas e, sobretudo no setor bélico, constituíram-se em prova definitiva de que quase nunca os discursos refletem o comportamento real dos governos.

Com o advento do Mercosul, enquanto alguns interesses convergiam na esfera econômica, verificou-se, na maior parte dos casos, postura divergente, e os assuntos estratégico-militares seguiram a passos miúdos.

Como lembravam autoridades argentinas e brasileiras, ainda é cedo para formalizar esses temas. Para o ex-chanceler Guido di Tella, "batalhões conjuntos, por enquanto são pura fantasia” (Bertolotto, 1997). O que não significa dizer que não sejam importantes. Contudo, uma coisa é considerá-los como tal, e outra é viabilizá-los na prática. No fundo, o grau de confiança recíproco é, ainda, muito limitado para tornar concretas tais propostas. Se há claras dificuldades para os países membros do Mercosul, que não conseguem solucionar seus próprios problemas, e a incapacidade para chegar-se a bom termo em temas políticos e econômicos do bloco, o que dizer, então, sobre questões mais delicadas como as políticas externa e de defesa comuns?

Os últimos dez anos de percalços enfrentados, em especial por Buenos Aires e Brasília, indicaram claramente que a colaboração faz parte das regras do jogo, assim como as próprias divergências. Nesse sentido, são compreensíveis as reclamações destemperadas quando um país não consegue resolver seus problemas domésticos, colocando a culpa no parceiro. Dessa forma, no final da década de 90, a desvalorização da moeda brasileira foi alvo de comentários quase impublicáveis, e apontada como responsável pela situação aguda enfrentada pela Argentina. Passaram a ser freqüentes, desde então, os discursos argentinos que pregavam o fim do próprio bloco. Os acontecimentos recentes do novo século caminham em trilha semelhante.

A percepção que os governantes têm é de que alguns anos são insuficientes para pensar em integração estratégico-militar. Se a Europa conduz tal processo há cinco décadas, sem chegar a resultados satisfatórios, o mesmo se pode dizer do cenário regional. Boas intenções são compartilhadas, mas não necessariamente realizadas. Além do mais, as mudanças de governo são, de igual modo, elementos a ser devidamente ponderados. Nada assegura que as decisões tomadas em um momento terão seqüência em outros, visto que os novos governantes podem adotar posicionamentos completamente distintos dos anteriores, em nome de novas prioridades, de novas conjunturas, de novas conveniências, etc.

As agendas externas de argentinos e brasileiros têm sido diametralmente opostas nos últimos anos. Enquanto a Argentina, durante os dois governos de Saul Menem optou pelo aprofundamento das relações com os norte-americanos, o Brasil esbarrou em uma série de contenciosos com os Estados Unidos, desde o relativo à propriedade 
intelectual ao meio ambiente, dos fármacos a um sem-número de posições contrárias no comércio internacional.

\section{NOTAS FINAIS}

Nada pode ser considerado irreversível nas relações internacionais. Alianças, acordos, tratados e organizações sobrevivem enquanto atenderem a todos os participantes.

Quando se pesam na balança os custos e benefícios, é evidente, só convém participar de uma empreitada, por melhor que esta seja, se os lucros forem maiores, ou se as perspectivas apontarem na direção em que todos ganhem em um jogo de soma variável positivo.

É assim que está escrito no Tratado de Rarotonga, que possibilita a saída de seus membros, quando problemas agudos afetarem seus interesses. Ou seja, atingirem seus interesses nacionais, em qualquer plano, seja no político, seja no econômico, e primordialmente no estratégico-militar. A Liga das Nações e o Tratado de Cartagena, apenas para lembrarmos dois casos, são amostras que ilustram com boa propriedade esse argumento.

Por isso, acordos em áreas sensíveis só serão realizados quando todos os participantes do Mercosul considerarem que seus interesses estão perfeitamente contemplados, que todos saem ganhando, e que as desconfianças não mais existem. Caso contrário, essas iniciativas jamais darão frutos, além de ficar tão-somente no plano retórico.

Como a experiência européia ilustra, há necessidade de um longo amadurecimento para que essas políticas sejam viáveis. A Otan é um bom exemplo. Apesar de o pilar europeu ter-se tornado possível, há alguns anos, na realidade ele só pode vigorar com a presença dos Estados Unidos, configurando-se uma tutela disfarçada.

Não se quer dizer aqui, que processos de integração jamais serão realizados, abarcando todas as variáveis possíveis. O cenário internacional, todavia, não dá indicações de quando isso se tornará factível. Ainda que os discursos da interdependência e da globalização enfatizem o surgimento de um único mundo, isso se dá apenas no plano estritamente discursivo. Como exemplificamos, nunca tivemos um período tão protecionista em que os valores nacionais falassem tão vigorosamente como agora. A globalização nada mais é do que um processo altamente competitivo entre a tríade que comanda o mundo - Estados Unidos, Europa e Japão -, e no qual estão excluídos os demais, pelo menos como decisões globais (Petrella, 1990).

Os interesses nacionais e o conceito de soberania - mesmo repensado - mais do que nunca sobrevivem e encon- tram-se presentes em todas as circunstâncias. Cada um procura salvaguardar seus próprios interesses, proteger suas fronteiras, seus domínios e fortalecer-se o mais possível, acumulando capacidades econômicas, bélica, ao mesmo tempo que investem em itens como ciência e tecnologia.

Assim, nada diferente se passa no Mercosul. As chances de se compatibilizar políticas externa e de defesa têmse manifestado apenas nos discursos, embora, efetivamente, algumas experiências tenham sido feitas nos últimos quinze anos. Todavia, isso tem-se demonstrado insuficiente em face das transformações internas e externas, em que cada um busca sua salvação individual, procurando ocupar espaço maior no cenário internacional.

Os blocos são utilizados pelos países para aumentar seus mercados, capacitar-se melhor em tecnologia, e para fazer frente a outros blocos. Entretanto, nada disso derruba o argumento original de que, enquanto não houver um governo mundial ou mesmo regional, abarcando três, seis ou duas centenas de países, torna-se inviável discutir e mesmo dividir decisões que só dizem respeito aos habitantes locais.

Comparando os anos anteriores com os anos 80, contudo, e apesar das divergências enfrentadas pelo Mercosul, a situação atual como relacionamento bilateral e multilateral, é sensivelmente melhor. O que não quer dizer que não perduram, ainda, desconfianças e discordâncias em muitos pontos que poderiam ser objeto de uma agenda comum. Tudo isso, entretanto, é perfeitamente natural, porque os personagens que se encontram em postos-chave nos dois governos, são os que passaram pelas duas etapas, anterior e atual às transformações nos cenários nacionais de cada um desses países, e do cenário regional.

Do mesmo jeito que militares exercem suas influências nos planos domésticos de vários países da região - já que são oficiais com idade mais avançada, logo, necessariamente situados no topo da hierarquia das Forças Armadas, - igual condição ocorre nos planos político e econômico, apesar de, nesses setores, profissionais mais jovens encontrarem-se em diversos cargos. Como se tem visto, porém, mesmo esses tem-se pautado muito mais por uma postura de confronto e de críticas aos seus vizinhos, do que de fato de estreitar colaboração.

Mudam-se as gerações, mas não o princípio de que cada um, tecnocrata ou militar, defenda os interesses específicos de seus países, até porque são eles os responsáveis pelas políticas macro e microeconômicas, em seus locais de origem. Agarram, com todas as forças, as decisões que beneficiem, em primeiro lugar, seu governo, seus partidos políti- 
cos, seus grupos, e só em último lugar a sociedade nacional e as relações mais amistosas com os demais países.

Possivelmente, ainda se passarão gerações para que a cooperação aprofunde-se, e que a integração se concretize de modo efetivo. Só aí as desconfianças desaparecerão, possibilitando que o aumento do grau de confiança recíproco molde as relações internacionais não só em termos bilaterais, como também multilaterais, nos âmbitos políticos, econômicos e culturais. Nesse sentido, desnecessário falar em termos estratégico-militares, porque essa variável seria relegada definitivamente a segundo plano. Contudo, as milhares de guerras travadas no período da era cristã parecem contradizer otimismo desse porte. As lutas cotidianas espelham o realismo com que cada Estado vê sua participação no plano regional e internacional, procurando, de qualquer forma assegurar sua sobrevivência, e ampliar seus espaços, muitas vezes à custa de seus vizinhos.

\section{NOTAS}

Este texto conta com recursos do CNPq, mediante Bolsa de Produtividade em Pesquisa concedida ao autor, para desenvolvimento do projeto "As políticas sul-americanas de segurança regional".

1. Declaração transcrita do jornal O Estado de S.Paulo, 23/03/99.

\section{REFERÊNCIAS BIBLIOGRÁFICAS}

ARON, R. Paix et guerre entre les nations. Paris, Calmann-Lévy, 1962.

BARBOSA, R.A. A América Latina em perspectiva: a integração da retórica à realidade. São Paulo, Aduaneiras, 1991.

BERTOLOTTO, R. "Integração militar começa, mas é lenta". Folha de S.Paulo, 11/05/97, p.1-3.

CÂMARA DOS DEPUTADOS. Projeto Sivam - Audiências públicas 1995. Brasília, Comissão de Fiscalização Financeira e Controle da Câmara dos Deputados, 1996.

CAUBET, C. As grandes manobras de Itaipu. São Paulo, Acadêmica, 1989.

CEBRES. A Amazônia brasileira. Simpósio Cebres/Eceme. Rio de Janeiro, Cebres/Eceme, out. 1991.

CONSELHO DE SEGURANÇA NACIONAL. Desenvolvimento e segurança na região ao norte das calhas dos rios Solimões e Amazonas - Projeto Calha Norte. Brasília, Secretaria Geral do Conselho de Segurança Nacional, 1985.

DEUTSCH, K. El analisis de las relaciones internacionales. Buenos Aires, Paidós, 1970.
ESCOLA SUPERIOR DE GUERRA. Estrutura do poder nacional para $o$ ano 2001. Rio de Janeiro, Escola Superior de Guerra, 1990.

FORSYTH, M. "Thomas Hobbes e as relações exteriores dos Estados". Relações Internacionais. Brasília, Centro de Documentação Política da Universidade de Brasília, ano 3, n.5, jun. 1980, p.67-74.

HAAS, E.B. Beyond the Nation-State. Stanford, Stanford University Press, 1964.

HUntington, S. "Choque de civilizações”? Política Externa. São Paulo, Paz e Terra/Nupri-USP, v.2, n.4, mar.-abr. 1994, p.120-78.

LAHERA, E. e ORTUZAR, M. "Gasto militar y desarrollo en América Latina”. Revista de la Cepal. Santiago, Cepal, n.65, ago. 1998.

MEY, E.A. "Abertura do $2^{\circ}$ Simpósio de estudos estratégicos argentino-brasileiro". Politica e Estratégia. São Paulo, Centro de Estudos Estratégicos, v.VI, n.3, jul.-set. 1988, p.341-42.

MINISTÉRIO DAS RELAÇÕES EXTERIORES. Tratado de Cooperação Amazônica. Brasília, Ministério das Relações Exteriores, 1978.

Resenha de Política Exterior do Brasil, número especial sobre Zona de Paz e de Cooperação no Atlântico Sul. Brasília, Ministério das Relações Exteriores, 1989.

MiYAmoto, S. "O Brasil e o Pacto do Atlântico Sul”. Revista de Cultura Vozes, Petrópolis, Vozes, ano 79, v.LXXIX, n.4, maio 1985, p.20-30.

OTAN. The Alliance's Strategic Concept. Disponível em: <http:// www.nato.int/docu/review>.

PETRELlA, R. "As duas faces da economia global". O Estado de S.Paulo, 18/03/90, p.40.

PRESIDÊNCIA DA REPÚBLICA. "Política de Defesa Nacional". Parcerias Estratégicas. Brasília, Centro de Estudos Estratégicos da Secretaria de Assuntos Estratégicos, v.1, n.2, 1996, p.7-15.

REVISTA BRASILEIRA DE POLÍTICA INTERNACIONAL. Número especial sobre a Amazônia. Revista Brasileira de Politica Internacional. Rio de Janeiro, Ibri, ano XI, n.41-2, mar.-jun. 1968.

SARDENBERG, R. Estudo das Relações Internacionais. Brasília, Editora da Universidade de Brasília, 1982.

“A estratificação internacional nos anos 90”. In: FONSECA Jr. e LEÃO, V.C. (orgs.). Temas de política externa. Brasília/ São Paulo, Fundação Alexandre Gusmão/IPRI/Ática, 1989.

THUROW, L. Cabeça a cabeça. São Paulo, Rocco, 1993.

VICENTINI, P.H. A Organização do Tratado do Atlântico Norte (Otan) e a incorporação das operações de paz no pós-guerra fria - a intervenção na Bósnia-Herzegovina (1992-1998). Dissertação de Mestrado. Brasília, Departamento de Relações Internacionais da Universidade de Brasília, 1998.

WALDNER, T.G. "Propósitos do simpósio". Política e Estratégia. São Paulo, Centro de Estudos Estratégicos, v.5, n.3, jul.-set. 1987, p.291-92.

Shiguenoli Miyamoto: Professor do Departamento de Ciência Politica do Instituto de Filosofia e Ciências Humanas da Unicamp, Coordenadordegraduaçãodocursode Ciências Sociais (shiguenoli@globo.com). 